\title{
Effect of growing strawberries with superimposed levels of cropgutters on yield and quality
}

\author{
J.-P. Bosc and A. Grisey \\ Ctifl, Centre de Balandran, Bellegarde, France
}

\section{Summary}

This experiment was carried out to assess the effect of increasing plant density by superimposing immovable levels of cropgutters. The greenhouse glazing was an air-inflated double layer of F-CLEAN ${ }^{\circledR}$, a specific version of ethylene tetrafluoroethylene. The inside layer was diffused F-CLEAN ${ }^{\circledR}$, in order to reduce the direct shading of the lower gutters by the upper levels. In this multi-span greenhouse were arranged, each in an 8-m wide span: a) the traditional single-level crop of 7 cropping lines, density 8.75 plants $\mathrm{m}^{-2}$; b) two levels of five cropping lines each (12.5 plants $\mathrm{m}^{-2}$ ); $\mathrm{c}$ ) three levels of five cropping lines each (18.75 plants $\mathrm{m}^{-2}$ ). In the two- and three-level system, the immovable cropgutters were vertically aligned: all the cropping operations could be done from the ground or using mobile platforms to adjust the working height to the upper levels. Two early cultivars, 'Gariguette' and 'Ciflorette', were grown as a soilless heated crop with trayplants planted on 14 December 2015. PAR light at the top of the canopy was reduced on the lower and the intermediate levels of the two- and three-level disposition; the highest reduction was measured on the lowest level of the three-level disposition. The changes observed in the content of total soluble solids (\% Brix) and titratable acidity due to shading remained acceptable. Yield per plant was significantly reduced on the lower and intermediate levels of the three-level disposition, but not on the lower level of the two-level disposition, nor on the upper levels of both dispositions. However, with two and three levels, the higher density per square meter led to a higher yield per square meter, compared to the traditional single-level crop: $+\mathbf{4 0 \%}$ (two-level system) and $+82 \%$ (three-level system) for 'Gariguette', $+48 \%$ and $+86 \%$ for 'Ciflorette'.

Keywords

vertical farming, soilless culture, plant density, fruit quality

\section{Introduction}

In France, soilless cultivation of strawberry is used to produce high quality and tasty fruit, and heating conditions enable the harvest to start in February, with two subsequent flushes of fruit production. This production system is commercially competitive with Spanish and Moroccan production in terms of earliness. Soilless culture under multiple tunnels or glasshouses has increased considerably for early production (Neri et al., 2012; Eckert, 2014). Because of the

\section{Significance of this study}

What is already known on this subject?

- For strawberry soilless cultivation, increasing plant density is a way to obtain a higher yield per greenhouse area. As horizontal use of the greenhouse is limited, a three-dimensional use was investigated with various systems throughout the world. All the systems have to cope with light deficiency, and subsequent loss of fruit quality, due to shading by the structural components.

\section{What are the new findings?}

- This manuscript presents new three-dimensional systems for higher densities, with highly elevated, superimposed and fixed crop gutters associated with a long-lasting diffuse plastic for greenhouse glazing. These dispositions promoted yield per greenhouse area, and the balance between light heterogeneity, fruit per plant production and fruit quality is attractive.

What is the expected impact on horticulture?

- These horizontal multi-level systems enhance high picking speed and cropping operations: mobile platforms adjust the working height and their movement is mainly horizontal. Yield increase per greenhouse area increases the heating efficiency (similar heating consumption for higher fruit production).

high cost of equipment and inputs, soilless heated cultivation is economically viable only for high and early yield crops. 'Gariguette' and 'Ciflorette' cultivars are cropped in this cultivation system to meet French consumer demand with a high quality fruit, particularly its balance between sweetness and acidity.

Increasing plant density is a way to obtain a higher yield per greenhouse area. Removing the path between each line of gutters increases horizontal efficiency. Nagasaki et al. (2013) developed a high-density system utilizing horizontally movable hanging gutters that held nine lines instead of six in an 8-m wide greenhouse. Hidaka et al. (2016) improved the productivity of this system with combinational environmental control (supplemental lighting, elevated $\mathrm{CO}_{2}$, air temperature). Hayashi et al. (2011) documented a circulating-type movable bench system for strawberries, with horizontal movement of planting benches. Plant density obtained using this highly mechanized system is 16 to 20 plants $\mathrm{m}^{-2}$. Commercial devices are available in Europe, and already in use on a commercial scale in a few production sites in France, 
with gutters very close together on the same level, moving up and down one out of every two gutters together: an 8-m wide span can hold ten lines instead of seven.

As horizontal use of the greenhouse is limited, a three-dimensional use offers new possibilities to increase plant density. Takeda (1999) reviewed vertical hydroponic systems (vertical polyethylene bag, PCV pipe column, column of interlocking square pots) and reported plants grown in these high plant density systems neither grow uniformly, nor produce similar plant yields due to the heterogeneity of the light reaching the canopy. Recently, Murthy et al. (2017) documented a commercial vertical hydroponic system (Verti-Grow System) in Indian conditions: limited light intensity in the lower tiers of the system caused a decrease in growth and yield (48\% decrease) of strawberry.

Wang et al. (2017) investigated a two- and three-level system (immovable), called " $H$ " type cultivation frame, in a solar greenhouse in Chinese (Beijing) conditions, the upper level being $1.60 \mathrm{~m}$ high from the ground. Melis et al. (pers. commun.) described a two-level system, adding three upper movable levels above the traditional seven horizontal lines ("Meerle high level system") in an 8-m wide span. Hidaka et al. (2012) used a multi-level system, with gutters moving up and down periodically to ensure equal light conditions. In all these systems, light deficiency is a critical point for plant production related to photosynthesis deficiency (Choi et al., 2014, 2016), but initiation problems (Bosc et al., 2012) or fruit albinism (Sharma et al., 2006) did not occur.

In the present study, a new system was investigated in southern France: immovable gutters were stacked in order to achieve a two- and three-level disposition. Frequent fluctuations in light intensity are caused by the direct shading of the lower levels by the upper levels in superimposed gutters. Direct shading of the lower levels by the upper levels was supposed not to be uniform during the day and the season, quite similar to the situation of roof-mounted photovoltaic panels. Light diffusion films appeared to be an option to achieve a more uniform light in greenhouses (Tani et al., 2014).

Ethylene tetrafluoroethylene, also known under its horticultural trade name F-CLEAN ${ }^{\circledR}$, was mentioned as a long-lasting plastic material (more than 15 years) with a high light transmission, good anti-drop and self-cleaning properties, and a double layer enabling high thermal insulation for greenhouse glazing (Kempkes et al., 2017). This greenhouse glazing was investigated in the same location for tomato crops (Grisey et al., 2014). Inside the greenhouse, immovable gutters were stacked in order to achieve a two- and three-level disposition. This experiment evaluated light conditions, yield and fruit quality with French early short-day cultivars 'Gariguette' and 'Ciflorette'.

\section{Materials and methods}

The experiment was located at the Ctifl Balandran Centre (Southern France, Mediterranean conditions, $04^{\circ} 28^{\prime} \mathrm{E}$, $\left.43^{\circ} 45^{\prime} \mathrm{N}\right)$. The greenhouse glazing was an air-inflated double layer of F-CLEAN ${ }^{\circledR}$ (AGC Glass Company), a specific version of ethylene tetrafluoroethylene. The outside layer is clear with a thickness of $100 \mu \mathrm{m}$ and the inside layer is diffuse with a thickness of $60 \mu \mathrm{m}$. In this multi-span greenhouse, the following cropping systems were arranged, each in an 8-m wide span: a) the traditional single-level crop of 7 cropping lines, density 8.75 plants $\mathrm{m}^{-2}$; b) two levels of five cropping lines each (12.5 plants $\left.\mathrm{m}^{-2}\right)$; c) three levels of five cropping lines each (18.75 plants $\mathrm{m}^{-2}$ ). In the two- and three-level systems, the immovable cropgutters were vertically aligned (Figure

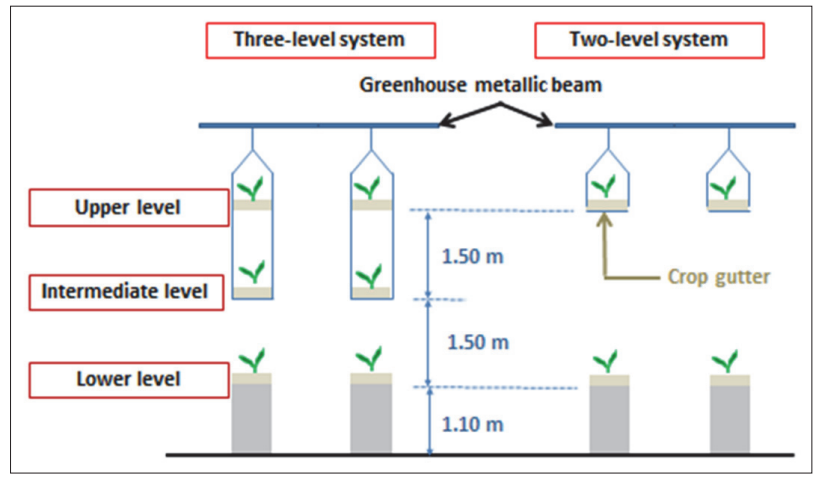

FIGURE 1. Schematic diagram of the three- (left) and twolevel (right) dispositions. Lower level cropgutters were laid on a support placed on the greenhouse floor, while intermediate and upper level cropgutters were supported by wire ropes fixed on greenhouse horizontal beams.

1): all the cropping operations could be done without any additional help (lower level) or using mobile platforms to adjust the working height to the upper levels (Figure 2). Two early French cultivars, 'Gariguette' and 'Ciflorette', were arranged in each disposition with three adjacent replications of 35 trayplants. Plants were placed in plastic bags containing substrate with a density of 10 plants per linear meter of gutter for each system. The substrate was a commercial mix of peat and composted pine bark (Dumona 16/6). The culture was grown as a soilless heated crop with trayplants planted on 14 December 2015. All the plants were supplied with the same nutrient solution through a drip irrigation system, electrical conductivity varying from $1.2 \mathrm{dS} \mathrm{m}^{-1}$ to $1.7 \mathrm{dS} \mathrm{m}^{-1}$ according to plant development stage. The same irrigation

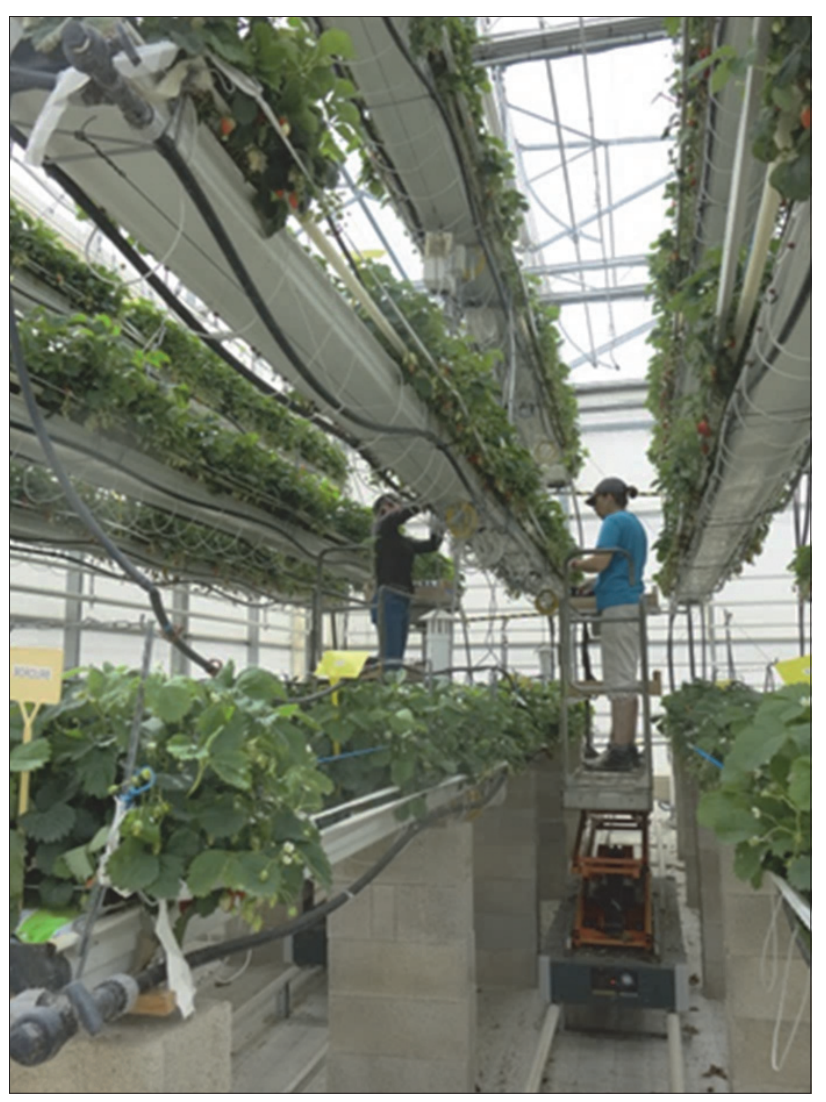

FIGURE 2. Fruit picking on mobile platforms to adjust the working height to the upper levels of the three-level system. 
dose and frequency were given to the plants in the multilayer system and the control (traditional single-level crop) to achieve a $20 \%$ drainage rate on the control. Photosynthesis Photon Flux Density radiation was measured at the top of the canopy on the centre of each level using a Kipp \& Zonen PQS1 sensor and the Daily Light Integral (DLI) was calculated on a sunny (March $2^{\text {nd }}$ ) and a rainy (March $16^{\text {th }}$ ) day. Fruits were picked twice a week and marketable yield, number of fruits and mean fruit weight were assessed.

Fruit quality was determined on the basis of soluble solids content and titratable acidity on 30 -fruit samples. Thirty fruit sampled on each replication of the two-level, three-level and single level systems were frozen and stored at $-25^{\circ} \mathrm{C}$ until analysis. The whole samples were thawed and macerated using a commercial blender (Waring Commercial, USA). Total soluble solids (TSS) content was measured as \%Brix in a few drops of the pulp using a digital refractometer (ATAGO Co., Ltd., Tokyo, Japan). Titratable acidity was determined using an automatic titrator (Crison Instruments S.A., Barcelona, Spain) which measured the number of meq $\mathrm{NaOH} 100 \mathrm{~g}^{-1}$ of pulp to reach $\mathrm{pH} 8.2$.

Statistical analysis was performed separately for 'Gariguette' and 'Ciflorette'. Each level of the two- and three-level system, and the single-level crop were considered as treatments in a three replications design (three adjacent replications of 35 trayplants). ANOVAs were used to test the marketable yield, number of fruits, mean fruit weight, TSS content and titratable acidity. The significance of differences between means among the respective treatments was tested using the Newman-Keuls test. The $\mathrm{p}<0.05$ was considered significant.

\section{Results and discussion}

\section{Photosynthetic photon flux density measurements}

Typical diurnal changes in photosynthetic photon flux density (PPFD) on a sunny day are shown in Figure 3. PPFD in the two and- and three-level systems showed a pattern similar to that measured on the single level system until 10:00 am. In the three-level system between 10:00 am and 3:00 pm, PPFD on the lower level ranged from $100 \mu \mathrm{mol}$ $\mathrm{m}^{-2} \mathrm{~s}^{-1}$ to $300 \mu \mathrm{mol} \mathrm{m} \mathrm{m}^{-2} \mathrm{~s}^{-1}$, the intermediate level from $100 \mu \mathrm{mol} \mathrm{m}^{-2} \mathrm{~s}^{-1}$ to $650 \mu \mathrm{mol} \mathrm{m}^{-2} \mathrm{~s}^{-1}$, with less effective shading from 2:00 pm to 3:00 pm. In the two-level system, PPFD on the lower level exhibited the same evolution as on the single level until 11:30 am $\left(\sim 500 \mu \mathrm{mol} \mathrm{m}^{-2} \mathrm{~s}^{-1}\right)$, and then shading had a strong effect until 2:00 pm $\left(\sim 300-400 \mu \mathrm{mol} \mathrm{m}^{-2} \mathrm{~s}^{-1}\right.$. PPFD on the upper levels of both multi-level systems had a quite similar pattern as on the single layer: fluctuations within $200 \mu \mathrm{mol} \mathrm{m}^{-2} \mathrm{~s}^{-1}$ to $850 \mu \mathrm{mol} \mathrm{m}^{-2} \mathrm{~s}^{-1}$. Sudden simultaneous drops in PPFD for all systems revealed temporary cloud shading. PPFD values within different levels are not proportional on a sunny day interval. Differentiated evolutions between levels are related to specific position of the span metallic

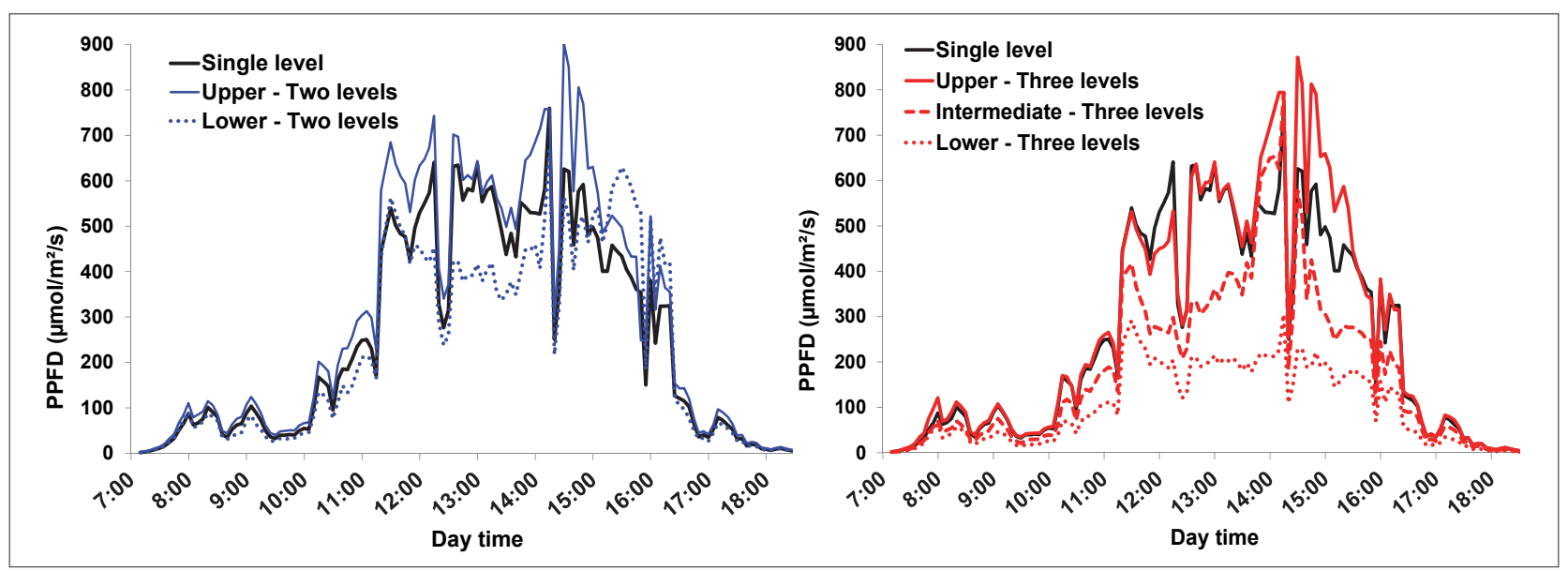

FIGURE 3. Effect of level disposition on Photosynthetic Photon Flux Density (PPFD) at the top of the canopy on a sunny day (left: single-level and two-level disposition, right: single-level and three-level disposition).

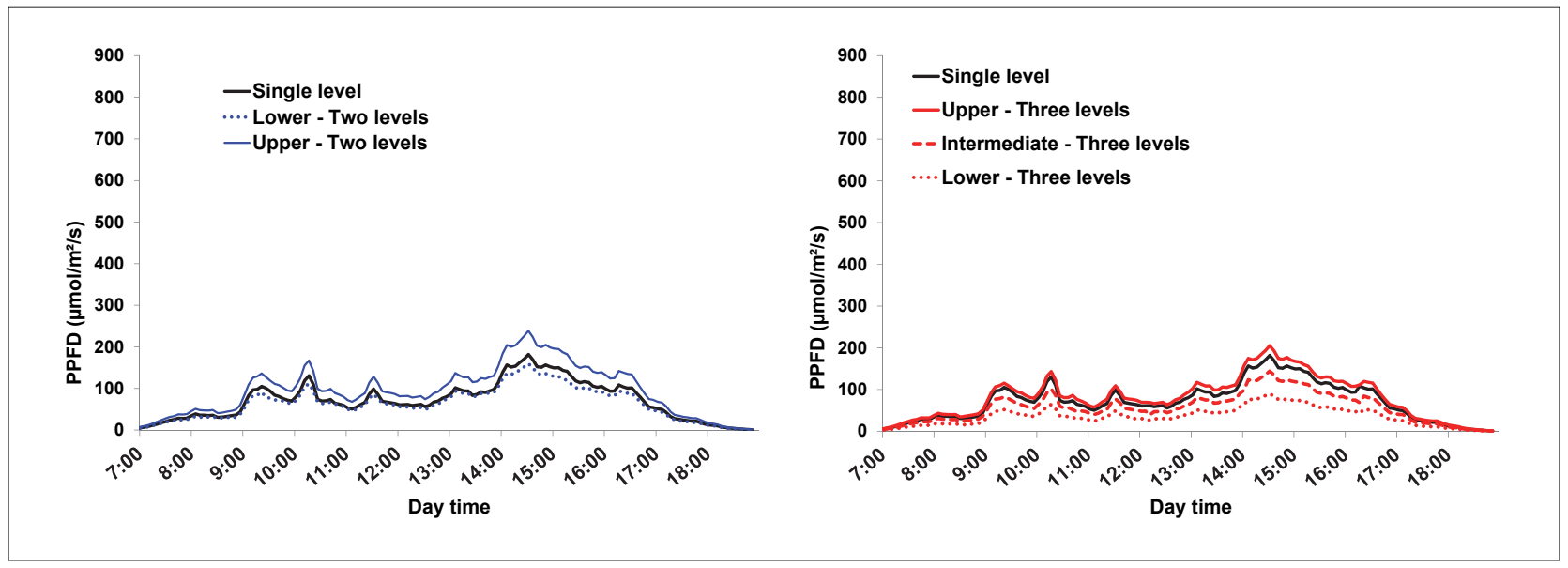

FIGURE 4. Effect of level disposition on Photosynthetic Photon Flux Density (PPFD) at the top of the canopy on a rainy day (left: single-level and two-level disposition, right: single-level and three-level disposition). 
TABLE 1. Effect of level disposition on Daily Light Integral received at the top of the canopy.

\begin{tabular}{llcc}
\hline \multirow{2}{*}{$\begin{array}{l}\text { Level } \\
\text { disposition }\end{array}$} & Position & \multicolumn{2}{c}{ Daily Light Integral $\left(\mathrm{mol} \mathrm{m}^{-2} \mathrm{~d}^{-1}\right)$} \\
\cline { 3 - 4 } & & $\begin{array}{c}\text { Sunny day } \\
(\text { March 2 }\end{array}$ & $\begin{array}{c}\text { Rainy day } \\
\left(\text { March } 16^{\text {th }}\right)\end{array}$ \\
\hline Single level & 10.4 & 3.1 \\
Two levels & Lower & 9.5 & 2.7 \\
& Upper & 12.4 & 4.1 \\
Three levels & Lower & 4.3 & 1.5 \\
& Intermediate & 7.6 & 2.4 \\
& Upper & 11.3 & 3.5 \\
\hline
\end{tabular}

structure and mainly to the variation in sunlight interception by upper levels due to the relative sun position. Hidaka et al. (2012) mentioned the PPFD reduction in November on the lower level of a two-level system but maximum value $(\sim 400$ $\left.\mu \mathrm{mol} \mathrm{m} \mathrm{m}^{-2} \mathrm{~s}^{-1}\right)$ and differences between levels were inferior (max. $\sim 200 \mu \mathrm{mol} \mathrm{m}^{-2} \mathrm{~s}^{-1}$ ). In the two-level system studied by Wang et al. (2017) (65 cm from top to top of the gutters), PPFD on the lower level was only $\sim 200-400 \mu \mathrm{mol} \mathrm{m}^{-2} \mathrm{~s}^{-1}$ whereas PPFD on the upper level ranged between $400 \mu \mathrm{mol}$ $\mathrm{m}^{-2} \mathrm{~s}^{-1}$ and $1,000 \mu \mathrm{mol} \mathrm{m} \mathrm{m}^{-2} \mathrm{~s}^{-1}$ during the same period of the day. On a typical rainy day in our system (Figure 4), differences between levels varied only slightly both on the two-level system and on the three-level system: PPFD was $\sim 100 \mu \mathrm{mol}$ $\mathrm{m}^{-2} \mathrm{~s}^{-1}$ to $150 \mu \mathrm{mol} \mathrm{m}{ }^{-2} \mathrm{~s}^{-1}$ except for the lower level of the three-level system (PPFD $<100 \mu \mathrm{mol} \mathrm{m}^{-2} \mathrm{~s}^{-1}$ ).

On a typical sunny day (March $2^{\text {nd }}$ ), Daily Light Integral decreased from the upper level $\left(11.3 \mathrm{~mol} \mathrm{~m}^{-2} \mathrm{~d}^{-1}\right)$ to the intermediate $\left(7.6 \mathrm{~mol} \mathrm{~m}^{-2} \mathrm{~d}^{-1}\right)$ and lower $\left(4.3 \mathrm{~mol} \mathrm{~m}^{-2} \mathrm{~d}^{-1}\right)$ levels on the three-level system (Table 1). For the two-level system, the decrease at the lower level was less important $(9,5 \mathrm{~mol}$ $\left.\mathrm{m}^{-2} \mathrm{~d}^{-1}\right)$ compared to the upper level $\left(12.4 \mathrm{~mol} \mathrm{~m}^{-2} \mathrm{~d}^{-1}\right)$. On a rainy day (March $16^{\text {th }}$ ), differences between levels varied only slightly both in the two-level system and in the three-level system. The increase of Daily Light Integral difference for a sunny vs. rainy day was also mentioned by Choi et al. (2014) for a two-level system.

\section{Yield per plant}

The very first fruits were picked on February $17^{\text {th }}$ or $22^{\text {nd }}$ for all level dispositions. Marketable yield was higher for 'Gariguette' than for 'Ciflorette', and can be related to a higher fruit number (Table 2). Marketable yield was significantly reduced on the lower and intermediate levels of the three-level system for both cultivars. Compared to the single level, yield reduction was 31\% (lower level) and 19\% (intermediate level) for 'Gariguette' and 25\% (lower level) and $16 \%$ (intermediate level) for 'Ciflorette'. On the lower level, the lower productivity derived from fruit weight and fruit number. On the intermediate level, 'Ciflorette' exhibited both lower fruit weight and fruit number, whereas 'Gariguette' exhibited mainly a lower fruit number. The lower level of the two-level system did not significantly differ from the single level concerning marketable yield, average marketable fruit weight and marketable fruit number per plant. The upper levels of both systems were at least equivalent to the single level for all the plant production parameters. Marketable yield was higher for 'Gariguette' than for 'Ciflorette' in all the systems, and can be related to a higher fruit number. In the three-level system, yield decrease is $125 \mathrm{~g} \mathrm{plant}^{-1}$ for 'Gariguette' and 67 g plant $^{-1}$ for 'Ciflorette'. It strongly suggests that the 'Gariguette' and 'Ciflorette' cultivars have different cultivar-specific requirements for light intensity.

In Turkey, the cultivar 'Sweet Charlie' responded negatively to $50 \%$ constant shading for all of the yield parameters (Demirsoy et al., 2007), and increased fruit weight with constant shading was considered a result of reduced yield. Ferree and Stang (1988) also reported that constant shading reduced the number of fruits but increased fruit weight. In our most shaded conditions (lower or intermediate levels three-level system), low yield was concomitant with reduced number of fruits and with averaged commercial fruit weight decrease.

In Korea, for a December to March fruit production, Choi et al. (2014) stated that plants grown under higher light conditions showed greater fruit production than those grown under lowered light. Their results indicated that the light intensity serves a crucial role in the production of fruits, probably resulting from the higher photosynthetic performances

TABLE 2. Strawberry plant productive parameters as affected by level disposition. In the same column, different letters indicate significant differences within each cultivar, according to Newman-Keuls test, $p \leq 0.05$.

\begin{tabular}{|c|c|c|c|c|}
\hline Level disposition & Position & $\begin{array}{l}\text { Marketable } \\
\text { yield } \\
\left.\text { (g plant }^{-1}\right) \\
\end{array}$ & $\begin{array}{c}\text { Average marketable } \\
\text { fruit weight } \\
\text { (g fruit }^{-1} \text { ) }\end{array}$ & $\begin{array}{c}\text { Fruit number } \\
\text { per plant } \\
\text { (marketable) }\end{array}$ \\
\hline & & & 'Gariguette' & \\
\hline Single level & & 348 a & $14.5 \mathrm{a}$ & $24.1 \mathrm{~b}$ \\
\hline \multirow[t]{2}{*}{ Two levels } & Lower & $330 a$ & $13.8 \mathrm{ab}$ & $24.0 \mathrm{~b}$ \\
\hline & Upper & $355 a$ & $14.1 \mathrm{ab}$ & $25.3 a b$ \\
\hline \multirow[t]{4}{*}{ Three levels } & Lower & $239 c$ & $12.4 \mathrm{~b}$ & $19.3 d$ \\
\hline & Intermediate & $284 b$ & $13.0 \mathrm{ab}$ & $21.7 \mathrm{c}$ \\
\hline & Upper & $364 \mathrm{a}$ & $14.0 \mathrm{ab}$ & $26.1 \mathrm{a}$ \\
\hline & & & 'Ciflorette' & \\
\hline Single level & & $249 b$ & $15.3 \mathrm{a}$ & $16.3 a b$ \\
\hline \multirow[t]{2}{*}{ Two levels } & Lower & $252 a b$ & $15.2 \mathrm{a}$ & $16.6 a b$ \\
\hline & Upper & $265 a$ & $15.2 \mathrm{a}$ & $17.5 \mathrm{a}$ \\
\hline \multirow[t]{3}{*}{ Three levels } & Lower & $187 d$ & $13.6 \mathrm{~b}$ & $13.8 \mathrm{c}$ \\
\hline & Intermediate & $208 c$ & $13.7 b$ & $15.2 b$ \\
\hline & Upper & $254 a b$ & $15.7 \mathrm{a}$ & $16.1 \mathrm{ab}$ \\
\hline
\end{tabular}


TABLE 3. Effect of level disposition on commercial plant production per greenhouse square meter. Plant density refers to the total plant number present on the single level, the two levels or the three levels of each disposition. In the same column, different letters indicate significant differences according to Newman-Keuls test, $\mathrm{p} \leq 0.05$.

\begin{tabular}{lccc}
\hline \multirow{2}{*}{ Level disposition } & $\begin{array}{c}\text { Plant density } \\
\text { (plants } \mathrm{m}^{-2} \text { ) }\end{array}$ & \multicolumn{2}{c}{ Marketable fruit production $\left(\mathrm{kg} \mathrm{m}^{-2}\right)$} \\
\cline { 3 - 4 } & 8.75 & 'Gariguette' & 'Ciflorette' \\
\hline Single level & 12.5 & $3.05 \mathrm{c}$ & $2.18 \mathrm{c}$ \\
Two levels & 18.75 & $4.28 \mathrm{~b}$ & $3.23 \mathrm{~b}$ \\
Three levels & $5.54 \mathrm{a}$ & $4.06 \mathrm{a}$ \\
\hline
\end{tabular}

TABLE 4. Total soluble solids content - effect of level position on content for 'Gariguette' and 'Ciflorette' in March. In the same column, different letters indicate significant differences within each cultivar, according to Newman-Keuls test, $p \leq 0.05$. P-value refers to ANOVA test in each column.

\begin{tabular}{|c|c|c|c|c|c|c|c|c|}
\hline \multirow{3}{*}{ Level disposition } & \multirow{3}{*}{ Position } & \multicolumn{7}{|c|}{ Total soluble solids content (\%Brix) } \\
\hline & & \multicolumn{4}{|c|}{ 'Gariguette' } & \multicolumn{3}{|c|}{ 'Ciflorette' } \\
\hline & & $\begin{array}{c}\text { March } \\
1\end{array}$ & $\begin{array}{c}\text { March } \\
11\end{array}$ & $\begin{array}{c}\text { March } \\
18\end{array}$ & $\begin{array}{c}\text { March } \\
21\end{array}$ & $\begin{array}{c}\text { March } \\
8\end{array}$ & $\begin{array}{c}\text { March } \\
15\end{array}$ & $\begin{array}{c}\text { March } \\
21\end{array}$ \\
\hline Single level & & 8.6 & 8.7 & $9.4 \mathrm{a}$ & $9.6 \mathrm{c}$ & $9.6 \mathrm{a}$ & $10.7 \mathrm{bc}$ & $11.1 \mathrm{c}$ \\
\hline \multirow[t]{2}{*}{ Two levels } & Lower & 8.7 & 8.7 & $9.2 \mathrm{a}$ & $9.8 \mathrm{bc}$ & $9.7 \mathrm{a}$ & $11.1 \mathrm{ab}$ & $11.6 \mathrm{~b}$ \\
\hline & Upper & 8.8 & 8.6 & $10.0 \mathrm{a}$ & $10.6 \mathrm{a}$ & $10.1 \mathrm{a}$ & $11.5 \mathrm{a}$ & $12.4 \mathrm{a}$ \\
\hline \multirow[t]{3}{*}{ Three levels } & Lower & 8.3 & 7.8 & $8.0 \mathrm{~b}$ & $8.0 \mathrm{e}$ & $8.7 \mathrm{~b}$ & $10.3 c$ & $11.0 \mathrm{c}$ \\
\hline & Intermediate & 8.5 & 8.1 & $8.5 b$ & $9.0 d$ & $9.4 \mathrm{a}$ & $11.0 \mathrm{ab}$ & $11.3 b c$ \\
\hline & Upper & 8.8 & 8.0 & $9.7 \mathrm{a}$ & $10.2 a b$ & $9.9 \mathrm{a}$ & $11.2 \mathrm{ab}$ & $12.1 \mathrm{a}$ \\
\hline$P$-value & & n.s. & n.s. & *** & $* * *$ & ** & ** & *** \\
\hline
\end{tabular}

P-value: ${ }^{* *}<0.001 ;{ }^{* *}<0.01 ;{ }^{*}<0.05 ;$ n.s., non-significant.

TABLE 5. Titratable acidity - effect of level position for 'Gariguette' and 'Ciflorette' in March. In the same column, different letters indicate significant differences within each cultivar, according to Newman-Keuls test, $\mathrm{p} \leq 0.05$. P-value refers to ANOVA test in each column.

\begin{tabular}{|c|c|c|c|c|c|c|c|c|}
\hline \multirow[t]{3}{*}{ Level disposition } & \multirow[t]{3}{*}{ Position } & \multicolumn{7}{|c|}{ Titratable acidity (meq $\mathrm{NaOH} 100 \mathrm{~g}^{-1}$ of pulp) } \\
\hline & & \multicolumn{4}{|c|}{ 'Gariguette' } & \multicolumn{3}{|c|}{ 'Ciflorette' } \\
\hline & & $\begin{array}{c}\text { March } \\
1\end{array}$ & $\begin{array}{c}\text { March } \\
11\end{array}$ & $\begin{array}{c}\text { March } \\
18\end{array}$ & $\begin{array}{c}\text { March } \\
21\end{array}$ & $\begin{array}{c}\text { March } \\
8\end{array}$ & $\begin{array}{c}\text { March } \\
15\end{array}$ & $\begin{array}{c}\text { March } \\
21\end{array}$ \\
\hline Single level & & 17.1 & 15.5 & $16.1 \mathrm{a}$ & $15.6 \mathrm{a}$ & 12.3 & $12.4 \mathrm{bc}$ & 13.3 \\
\hline \multirow[t]{2}{*}{ Two levels } & Lower & 16.3 & 15.0 & $15.2 b$ & $14.9 a b$ & 12.5 & $12.1 \mathrm{c}$ & 13.0 \\
\hline & Upper & 16.3 & 14.5 & $15.4 \mathrm{ab}$ & $14.8 \mathrm{ab}$ & 12.4 & $13.2 \mathrm{a}$ & 14.0 \\
\hline \multirow[t]{3}{*}{ Three levels } & Lower & 16.6 & 15.3 & $14.1 \mathrm{c}$ & $13.2 \mathrm{c}$ & 12.8 & $11.9 \mathrm{c}$ & 13.1 \\
\hline & Intermediate & 16.4 & 14.9 & $15.1 \mathrm{~b}$ & $14.3 b$ & 12.9 & $12.7 b$ & 13.7 \\
\hline & Upper & 16.8 & 14.7 & $16.1 \mathrm{a}$ & $15.4 a b$ & 12.3 & $12.4 \mathrm{bc}$ & 13.9 \\
\hline$P$-value & & n.s. & n.s. & $* * *$ & *** & n.s. & $* * *$ & * \\
\hline
\end{tabular}

P-value: ${ }^{* *}<0.001 ;{ }^{* *}<0.01 ;{ }^{*}<0.05 ;$ n.s., non-significant.

displayed by plants grown under higher light. However, the two-level system led to a lower amount of light reaching the lower level. But fruit production per plant was not significantly reduced. Adding an intermediate level to achieve the three-level system, increased shading on the intermediate and lower levels. The production per plant decreased for both cultivars on the intermediate and particularly the lower levels. Plants were not able to produce as many commercial fruits, which, in the less favorable light environment, are smaller. This negative effect of upper level shading on plant production was mentioned by Hidaka et al. (2012) in Japan. Both three- and two-level systems in Chinese winter conditions led to lower yield per plant, average fruit weight and fruit number per plant (Wang et al., 2017), with a vertical distance of $65 \mathrm{~cm}$ between gutters. In our experiment, this vertical distance was higher, and 3 m distance (two-level system) did not decrease plant production whereas $1.5 \mathrm{~m}$ distance (three-level system) did.

\section{Yield per ground area}

The higher plant number per greenhouse ground area in the two- and three-level systems led to a higher yield per square meter compared to the traditional single-level crop (Table 3): $+123 \mathrm{~g} \mathrm{~m}^{-2}$ (two-level system) and $+249 \mathrm{~g} \mathrm{~m}^{-2}$ (three-level system) for 'Gariguette', $+105 \mathrm{~g} \mathrm{~m}^{-2}$ and $+188 \mathrm{~g} \mathrm{~m}^{-2}$ for 'Ciflorette', respectively (Table 3 ), considering the total production period. 'Gariguette' exhibited higher yields and yield increase, particularly with the three-level system. In Chinese conditions (Wang et al., 2017), the two-level system with a vertical distance of $65 \mathrm{~cm}$ (top-to-top of the gutters) 


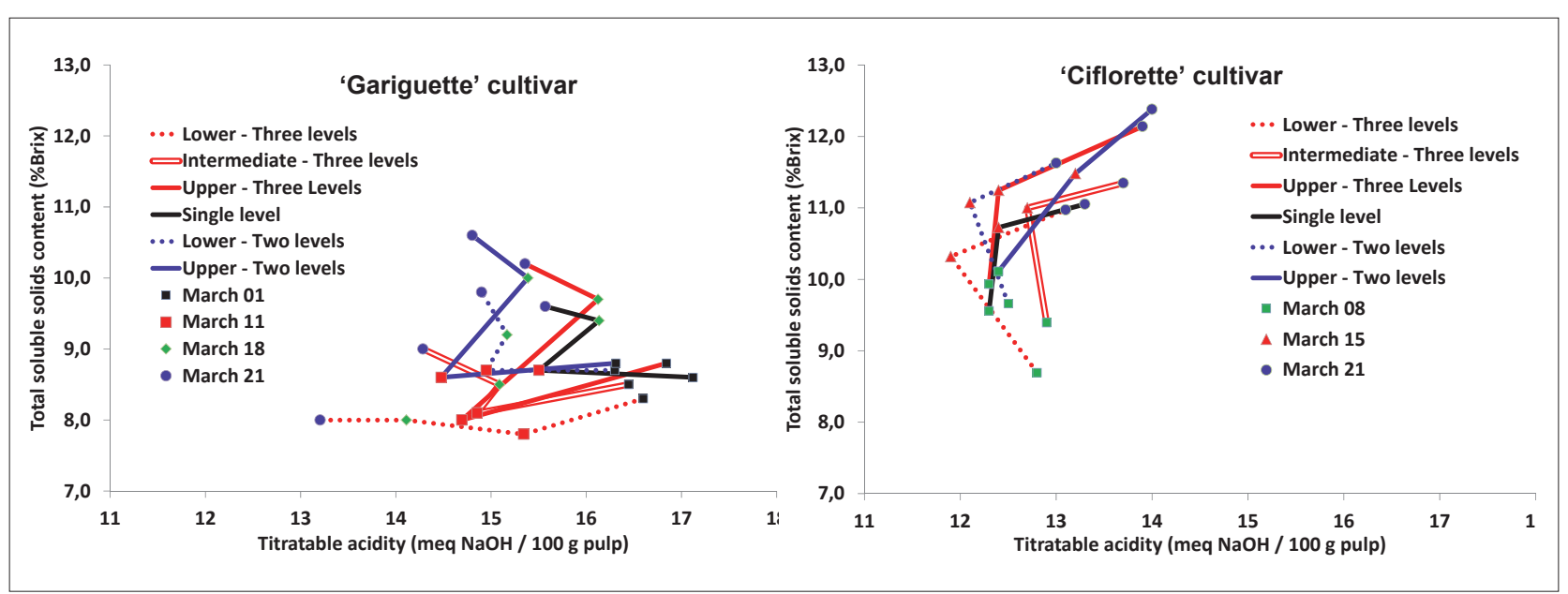

FIGURE 5. Effect of level position on evolution of soluble solids content vs. titratable acidity for 'Gariguette' (left) and 'Ciflorette' (right) in March. Each type of line refers to different level position and the point symbols refer to sample dates (three replications of thirty fruits).

achieved a better yield per ground area than the three-level system. In Japan, Hidaka et al. (2012) mentioned high density could compensate lower production per plant: the multi-layer system quadrupled the density but total yield per ground area only doubled. In our experiment, yield increase was proportional to density increase in the two-level system (density $+40 \%$, 'Gariguette' $+40 \%$, 'Ciflorette' $+48 \%$ ), but not in the three-level system: density $+114 \%$, 'Gariguette' $+82 \%$, 'Ciflorette' $+86 \%$. Sufficient distance between the gutters $(1.5 \mathrm{~m}$ in the present experiment) was an important factor to limit the decrease in yield per plant, so that plant density would be able to compensate.

Total soluble solids (TSS) content and titratable acidity

In March for 'Gariguette' (Table 4), the difference increased between the TSS content of the single-level system fruits and the lower level of the three-level system: TSS content values of the single-level were significantly higher on March $18^{\text {th }}$ and March $21^{\text {st }}$. However, the maximum difference was $1.6 \%$ Brix and the $\sim 8 \%$ Brix value for the lower level of the three-level system was stable and acceptable. The intermediate level (three-level system) showed significant but limited decreases (maximum $-0.9 \%$ Brix) on March $18^{\text {th }}$ and March $21^{\text {st }}$ when compared to the single level TSS content. For 'Ciflorette', the difference between the TSS content of the single-level system fruits and the lower level of the three-level system was only evident on March $8^{\text {th }}$ but not on further dates; TSS contents of the intermediate level was similar to that of the single level. For both cultivars, TSS content of fruits from the lower level of the two-level system did not show any significant decrease when compared to TSS values from the single level. The upper levels of both systems exhibited TSS contents similar to those of the single-level system (March $1^{\text {st }}$ to March 18 ${ }^{\text {th }}$ ) for 'Gariguette' and 'Ciflorette' and even superior on March $21^{\text {st. }}$.

Concerning titratable acidity (Table 5), 'Gariguette' fruits from the lower and the intermediate levels (three-level system) exhibited lower values than those of the single-level system, but 'Ciflorette' fruits did not. The lower level of the two-level system differed only once ('Gariguette' March $18^{\text {th }}$ ) from the single level for both cultivars, whereas the upper levels of both systems were similar.

Figure 5 shows the relative evolution of total soluble solids content versus titratable acidity. From March $1^{\text {st }}$ to March $21^{\text {st }}$ with 'Gariguette', the upper level of the three-level system exhibited the same evolution as the single level: an overall increase of TSS content with limited variation of titratable acidity, whereas the lower level of the three-level disposition showed a stable TSS content and a continuous decrease of titratable acidity. The intermediate level of the three-level system exhibited an intermediate evolution: limited variations of titratable acidity and limited increase of total soluble solids content. Both levels of the two-level system behave quite similarly to the single-level system: an acidity decrease from March $1^{\text {st }}$ to March $11^{\text {th }}$ and afterward, a TSS content increase with limited increase of titratable acidity. Concerning 'Ciflorette', all the levels exhibited an overall TSS increase from March $8^{\text {th }}$ to March $21^{\text {st }}$. The present three-level system behaved quite similarly to the two-level system mentioned by Choi et al. (2016) in which the fruits of the upper level had higher capacity to accumulate soluble sugars and organic acids than those of the lower level. Caruso and Villari (2003) also noticed a TSS and titratable acidity decrease from upper to lower level in a two-level system.

\section{Conclusion}

Cropping strawberries in stacked immovable gutters is a new concept: moving the greenhouse workers instead of the crop, in order to use the three-dimensional space of the greenhouse. Associated with diffused F-CLEAN ${ }^{\circledR}$ greenhouse, it allowed higher yields for French cultivars 'Gariguette' and 'Ciflorette', with no evidence of compromised fruit quality.

\section{References}

Bosc, J.P., Neri, D., Massetani, F., and Bardet, A. (2012). Relationship between plant architecture and fruit production of the short-day strawberry cultivar Gariguette. J. Berry Res. 2(2), 105-111. https:// doi.org/10.3233/JBR-2012-031.

Caruso, G., and Villari, G. (2003). Effect of nutritive solution EC and shading on the "fruit" quality of NFT-grown strawberry. Acta Hortic. 614, 719-726. https://doi.org/10.17660/ActaHortic.2003.614.107.

Choi, H.G., Moon, B.Y., and Kang, N.J. (2016). Correlation between strawberry (Fragaria ananassa Duch.) productivity and photosynthesis-related parameters under various growth conditions. Frontiers in Plant Sci. 7, 1607. https://doi.org/10.3389/ fpls.2016.01607. 
Choi, H.G., Moon, B.Y., Kang, N.J., Kwon, J.K., Bekhzod, K., Park, K.S., and Lee, S.Y. (2014). Yield loss and quality degradation of strawberry fruits cultivated under the deficient insolation conditions by shading. Hortic. Environ. Biotechnol. 55, 263-270. https://doi.org/10.1007/ s13580-014-0039-0.

Demirsoy, L., Demirsoy, H., Uzun, S., and Öztürk, A. (2007). The effects of different periods of shading on growth and yield in 'Sweet Charlie' strawberry. Europ. J. Hortic. Sci. 72, 26-31. http://www. jstor.org/stable/24126249.

Eckert, C. (2014). La fraise hors sol en France, un système de production à part entière. Infos-Ctifl 208, 56-11 (in French with English abstract).

Ferree, D.C., and Stang, E.J. (1988). Seasonal plant shading, growth, and fruiting in 'Earliglow' strawberry. J. Amer. Soc. Hortic. Sci. 113, 322-324.

Grisey, A., Rosso, L., Auger, E., Tisiot, R., and D’Amaral, F. (2014). Sustainable energy greenhouse - Results of the project: Reduction of energy consumption and energy storage in aquifer. Acta Hortic. 1037, 147-154. https://doi.org/10.17660/ActaHortic.2014.1037.14.

Hayashi, S., Saito, S., Iwasaki, Y., Yamamoto, S., Nagoya, T., and Kano, K. (2011). Development of circulating-type movable bench system for strawberry cultivation. JARQ 45, 285-293. https://doi.org/10.6090/ jarq. 45.285 .

Hidaka, K., Ito, E., Sago, Y., Yasutake, D., Miyoshi, Y., Kitano, M., Miyauchi, K., Okimura, M., and Imai, S. (2012). High yields of strawberry by applying vertically-moving beds on the basis of leaf photosynthesis. Environm. Control in Biol. 50(2), 143-152. https:// doi.org/10.2525/ecb.50.143.

Hidaka, K., Dan, K., Miyoshi, Y., Imamura, H., Takayama, T., Kitano, M., and Okimura, M. (2016). Twofold increase in strawberry productivity by integration of environmental control and movable beds in a large-scale greenhouse. Environm. Control in Biol. 54(2), 79-92. https://doi.org/10.2525/ecb.54.79.

Kempkes, F.L.K., Janse, J., and Hemming, S. (2017). Greenhouse concept with high insulating cover by combination of glass and film: design and first experimental results. Acta Hortic. 1170, 469-486. https://doi.org/10.17660/ActaHortic.2017.1170.58.

Melis, P. (2016). Meerle high level system: growing strawberries on different levels to obtain a higher yield. Oral communication presented at: VIII International Strawberry Symposium (Quebec, Canada).

Murthy, B.N.S., Karimi, F., and Laxman, R.H. (2017). Physiological performance reflecting in yield and quality of strawberry under vertical soilless culture system. Acta Hortic. 1156, 301-308. https:// doi.org/10.17660/ActaHortic.2017.1156.46.

Nagasaki, Y., Hayashi, S., Nakamoto, Y., Kawashima, H., and Kohno, Y. (2013). Development of a table-top cultivation system for robot strawberry harvesting. JARQ 47, 165-169. https://doi.org/10.6090/ jarq.47.165.

Neri, D., Baruzzi, G., Massetani, F., and Faedi, W. (2012). Strawberry production in forced and protected culture in Europe as a response to climate change. Can. J. Plant Sci. 92, 1021-1036. https://doi. org/10.4141/cjps2011-276.

Sharma, R.R., Patel, V.B., and Krishna, H. (2006). Relationship between light, fruit and leaf mineral content with albinism incidence in strawberry (Fragaria $\times$ ananassa Duch.). Sci. Hortic. 109, 66-70. https://doi.org/10.1016/j.scienta.2006.03.009.

Takeda, F. (1999). Out-of-season greenhouse strawberry production in soilless substrate. Adv. Strawberry Res. 18, 4-15.
Tani, A., Shiina, S., Nakashima, K., and Hayashi, M. (2014). Improvement in lettuce growth by light diffusion under solar panels. J. Agric. Meteor. 70, 139-149. https://doi.org/10.2480/ agrmet.D-14-00005.

Wang, C., Song, W., Zhao, S., and Qu, M. (2017). Effect of different combinations of H-type cultivation frames on light and strawberry growth and yield. Transact. Chinese Soc. of Agric. Eng. 33(2), 234239 (in Chinese with English abstract). https://doi.org/10.11975/j. issn.1002-6819.2017.02.032.

Received: Jun. 19, 2018

Accepted: Oct. 23, 2018

Address of authors:

Jean-Philippe Bosc* and Ariane Grisey

Ctifl (Centre Technique Interprofessionnel des Fruits et

Légumes), Centre de Balandran, 751 Chemin de Balandran,

30127 Bellegarde, France

* Corresponding author; E-mail: bosc@ctifl.fr

Tel.: +334660110 54; Fax: +33466016228 